\title{
Fundamentalismo da gestão encontra a descolonialidade: repensando estrategicamente organizações familiares
}

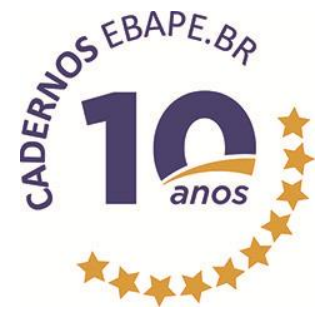

\author{
Management fundamentalism meets decoloniality: strategically rethinking family \\ organizations
}

\author{
Alexandre Faria ${ }^{1}$ \\ Sergio Wanderley ${ }^{2}$
}

\section{Resumo}

Por não terem sido convertidas pela globalização neoliberal em organizações de mercado governadas pelos fundamentos da visible hand, em desacordo com o fundamentalismo da gestão, organizações familiares continuam tendo papel estratégico no (e para o) resto do mundo. Engajamo-nos na opção descolonial para analisar neste artigo a trajetória de marginalização de organizações familiares no campo da gestão e, em especial, em gestão estratégica. Ao enfocar o âmbito da gestão estratégica da geopolítica do conhecimento em gestão, o artigo mostra que as seguidas crises da globalização neoliberal ocidental, liderada pelos EUA, e a correspondente ascensão do resto do mundo criaram condições tanto para a descolonização do campo da gestão quanto para o fortalecimento do fundamentalismo da gestão. Propomos, então, a descolonização da gestão e a desmarginalização das organizações familiares por meio da construção de uma área de estudo em estratégia no (a partir do) Brasil que problematize a gestão estratégica da geopolítica do conhecimento em gestão.

Palavras-chave: Organizações familiares. Fundamentalismo da gestão. Descolonialidade. Estratégia.

\begin{abstract}
As not have been converted by neoliberal globalization into market organizations governed by fundamentals of the "visible hand", disagreeing with management fundamentalism, family organizations still play a strategic role in (and to) the rest of the world. We engage with a decolonial approach to analyze in this article the marginalization pathway of family organizations in management and, especially, in strategic management. By focusing on the domain of strategic management of geopolitics of knowledge in management, the article shows that the repeated crises of the western neoliberal globalization, led by the USA, and the corresponding rise of the rest of the world have created conditions both for decolonizing the management field and for strengthening management fundamentalism. Thus, we propose to decolonize management and demarginalize family organizations by constructing a study area in strategy in (and from) Brazil that problematizes the strategic management of the geopolitics of knowledge in management.
\end{abstract}

Keywords: Family organizations. Management fundamentalism. Decoloniality. Strategic management

Artigo submetido em 03 de maio de 2013 e aceito para publicação em 19 de dezembro de 2013.

1

Doutor em Administração pela Universidade de Warwick/Inglaterra; Professor adjunto da Fundação Getulio Vargas/EBAPE. Endereço: FGV/EBAPE - Escola Brasileira de Administração Pública e de Empresas, Praia de Botafogo, 190 - 4ํㅜㄴ 5a andares, Botafogo, CEP 22253-900, Rio de Janeiro - RJ, Brasil. E-mail: alex.faria@fgv.br

2 Mestrado e doutorando em Administração pela Fundação Getulio Vargas/EBAPE; Professor extracarreira da Fundação Getulio Vargas.Endereço: FGV/EBAPE - Escola Brasileira de Administração Pública e de Empresas, Praia de Botafogo, 190 - 4ํㅜ e ${ }^{\circ}$ andares, Botafogo, CEP 22253-900, Rio de Janeiro - RJ, Brasil. E-mail: sergio.wanderley@fgv.br 


\section{Introdução}

Impulsionado principalmente pelo advento da globalização neoliberal ocidental, também denominada (neo)imperialismo neoliberal por áreas ignoradas pela literatura em gestão estratégica (DE GRAAF e VAN APELDOORN, 2011; STEGER, 2009), o conhecimento acadêmico em gestão tem experimentado um processo exponencial de crescimento e expansão. Esse processo, entretanto, não se caracteriza pela multipolaridade que supostamente deveria informar a gestão e outros campos do conhecimento no contexto pós-Guerra Fria. Ao contrário, a continuada hegemonia do mundo euro ou anglo-americano contrasta marcadamente com as seguidas crises da ordem neoliberal ocidental e a ascensão das economias emergentes e outras partes do resto do mundo (COOKE e FARIA, 2013; MURPHY e ZHU, 2012; JACK et al., 2012).

As seguidas crises da globalização neoliberal ocidental, liderada pelos EUA, e a correspondente ascensão do resto do mundo criaram condições tanto para a descolonização do campo da gestão quanto para o fortalecimento do fundamentalismo da gestão. Isso ajuda a explicar o crescente volume de conhecimento em gestão e a notável expansão do escopo da área de gestão estratégica. Em conjunto, ambos reforçam a gestão estratégica da geopolítica do conhecimento baseada nos fundamentos da universalidade eurocêntrica, em detrimento de um crescente número de vozes que engaja e defende a pluriversalidade descolonialista. De modo similar aos fundamentos do fordismo e de acordo com os pressupostos imperialistas da tese do fim da história (FUKUYAMA, 1992), do fundamentalismo de mercado (STIGLITZ, 2002) e da globalização neoliberal (STEGER e ROY, 2010), o fundamentalismo da gestão prescreve que tudo deve e pode ser transformado em gestão, desde que seja a "nossa gestão".

Vivemos então uma crise geoepistêmica crucial no campo da gestão. Ela traz implicações significativas para lidarmos com as seguidas crises da ordem neoliberal ocidental e a ascensão do resto do mundo. Neste artigo, denominamos esse quadro de crise fundamentalismo da gestão e defendemos a descolonização do campo de gestão por meio de teorizações que problematizem a gestão estratégica da geopolítica do conhecimento com base em perspectivas "outras" que podem ajudar a construir um mundo no qual diferentes mundos (e conhecimentos) podem coexistir (MIGNOLO, 2011).

A despeito dos inúmeros debates sobre gestão, é crescente o número de áreas do conhecimento e práticas que vêm sendo classificadas como pertencentes à área de gestão estratégica nos EUA. Essa área lida, nos dias de hoje, com temas de elevada importância geopolítica, tais como pobreza global, desenvolvimento internacional, crise do capitalismo e reformas institucionais em economias emergentes (p. ex., PORTER e KRAMER, 2011). O crescente número de ameaças no resto do mundo detectadas pelos estrategistas dos EUA tem justificado a expansão de escopo da área de gestão estratégica. Esse quadro é explicado pelas seguidas crises da globalização neoliberal ocidental, liderada pelos EUA, por meio de "dominação sem hegemonia" (ARRIGHI, 2007; MAHBUBANI, 2009), e a ascensão do resto do mundo. As organizações familiares, por exemplo, ao serem reconhecidas como importantes para a ascensão do resto do mundo, foram incluídas pela área de gestão estratégica sob uma perspectiva colonialista que não foi problematizada no resto do mundo. Em outras palavras, por contrariar o fundamentalismo da gestão e por ser importante para a construção de alternativas à ordem dominante, a área de gestão estratégica (dominada pelos EUA) optou recentemente pela inclusão (i. e., por meio de uma desmarginalização colonialista) das organizações familiares. Tais processos de inclusão colonialista pela área de gestão estratégica, que poderiam ser problematizados pela área de gestão estratégica no resto do mundo se a gestão estratégica da geopolítica do conhecimento em gestão fosse reconhecida por acadêmicos e suas instituições, reforçam o fundamentalismo da gestão e a necessidade de engajamento do resto do mundo com a opção descolonialista.

Devido às fortes restrições impostas pela colonialidade sob uma perspectiva de longa duração, a resiliência do fundamentalismo da gestão ainda não foi problematizada com o necessário rigor no resto do mundo. Neste artigo, por meio de engajamento "estratégico" com a opção descolonial, argumentamos que o fundamentalismo da gestão não seria possível sem o advento da gestão científica e a construção da ciência da gestão/administração nos EUA. Também mostramos que tal resiliência não existiria se a "ciência" (moderna) não tivesse sido construída no Ocidente, acompanhada e viabilizada pelo rebaixamento, pela subalternização 
e pela racialização de diversas outras epistemes e conhecimentos/saberes do "resto do mundo" (SANTOS, NUNES e MENESES, 2008; CORONIL, 1996). Fundamentalismo da gestão se confunde não apenas com fundamentalismo de mercado (da globalização neoliberal ocidental, liderada pelos EUA), mas, em especial, com fundamentalismo eurocêntrico (DUSSEL, 1993). O artigo conclui que uma perspectiva "outra", enunciada no resto do mundo e com base na construção de uma área de "estudos em estratégia", que problematize a gestão estratégica da geopolítica do conhecimento por meio da opção descolonial, é importante para a desmarginalização "estratégica" das organizações familiares.

Este artigo está dividido em seis partes, incluindo esta introdução. Na segunda parte, apresentamos os principais fundamentos do projeto de modernidade-(des)colonialidade desenvolvida na América Latina e a opção descolonial. Na terceira, analisamos o fundamentalismo da gestão por meio de uma perspectiva histórica de longa duração. Na quarta, argumentamos que os processos de construção e disseminação do conhecimento de gestão dos EUA para o resto do mundo no contexto da Guerra Fria marginalizaram as organizações familiares e restringiram o reconhecimento da geopolítica do conhecimento pela área de gestão estratégica no resto do mundo. Na quinta, argumentamos que processos assimétricos de gestão estratégica da geopolítica do conhecimento vêm fortalecendo a marginalização das possibilidades de repensar estrategicamente as organizações familiares. Na parte final, argumentamos que uma perspectiva de geopolítica do conhecimento é necessária para a desmarginalização "estratégica" de organizações familiares no Brasil a partir da opção descolonial.

\section{Engajando-se na Opção Descolonial}

Apesar da inegável importância das organizações familiares no Brasil, a literatura sobre o tema ainda é incipiente, em especial no que diz respeito ao reconhecimento de questões de geopolítica do conhecimento (p. ex., PAIVA, OLIVEIRA e MELO, 2008). Ou seja, a organização familiar costuma ser tratada como um tipo inferior - a ser "corrigido" - por ser comparado com as virtudes da grande corporação moderna. Esta foi naturalizada como padrão universal pelo fundamentalismo da gestão da mesma forma como o Ocidente foi naturalizado como civilização e o resto do mundo como barbárie pela modernidade eurocêntrica.

Essa imposição "natural" de um tipo de organização em detrimento de outro(s) é descrita por autores descoloniais como manifestação de colonialidade epistêmica (IBARRA-COLADO, 2006). Colonialidade epistêmica é um dos efeitos e condições do quadro dominante de gestão estratégica da geopolítica do conhecimento em diversas áreas, incluindo a de gestão, pelos defensores da universalidade eurocêntrica. Esse tipo de colonialidade é marcado pela imposição de conhecimentos produzidos a partir de uma "outra" realidade e que se sobrepõe às práticas e conhecimentos locais, terminando por provocar a subalternização destes (IBARRA-COLADO, 2006). A fim de escapar desse quadro de dominação (via mecanismos de gestão estratégica da geopolítica do conhecimento que a colonialidade epistêmica tornou invisíveis), este artigo engaja-se na opção descolonial para promover a construção de uma área de estudos em estratégia no Brasil que reconheça a gestão estratégica da geopolítica do conhecimento e crie, assim, condições para a desmarginalização das organizações familiares (não estamos argumentando que organizações familiares sejam intransitivamente virtuosas) e a contenção da trajetória de expansão da área de gestão estratégica por meio da inclusão de "outros" por meio de uma perspectiva colonialista.

Um dos principais autores do projeto modernidade/colonialidade/descolonialidade (MCD), que informa a opção descolonial, é o filósofo e semiólogo argentino Walter Mignolo. Mignolo se baseia principalmente nos conceitos desenvolvidos pelo filósofo argentino Enrique Dussel (1993), e pelo sociólogo peruano Anibal Quijano (2000). Esse projeto considera-se herdeiro de teorizações descoloniais produzidas na América Latina, em especial a teoria da dependência e a teologia da libertação (ESCOBAR, 2007), e representa uma continuação da Conferência de Bandung de 1955, na qual 29 países da Ásia e África se encontraram para propor a descolonização do capitalismo e do comunismo (MIGNOLO, 2013). Segundo Mignolo (2011) a "colonialidade" é o lado sombrio e constitutivo da modernidade eurocêntrica. Modernidade e colonialidade 
são partes inseparáveis do mesmo fenômeno e surgem simultaneamente com a "descoberta" da América por Cristóvão Colombo em 1492, e não somente nos séculos XVII/XVIII (como se fosse um fenômeno derivativo da modernidade), tal como proposto pela versão eurocêntrica da modernidade eurocêntrica (DUSSEL, 1993).

"Colonialidade" é um conceito criado pelo projeto MCD para designar a dominação de poder, do ser, e do conhecimento. Sob uma perspectiva histórica da longa duração, como nas teorizações de capitalismo de Braudel, Wallerstein e Arrighi, colonialidade difere de colonialismo por não se referir a um período histórico fixo estabelecido arbitrariamente por analistas. Colonialidade é uma estratégia de dominação que se baseia na distinção racial entre conquistadores e conquistados e na estrutura hierárquica correspondente de divisão de trabalho e de geopolítica de produção de conhecimento.

Mesmo após o suposto término do período de dominação pelo colonialismo europeu na África e Ásia, por exemplo, a colonialidade de poder como princípio e estratégia de dominação e controle permanece. Um dos elementos da colonialidade de poder é o encobrimento de conhecimentos e histórias locais pela episteme totalitária da modernidade eurocêntrica - uma epistemologia territorial e imperial que inventou e estabeleceu as categorias que distinguem racial e hierarquicamente pessoas e regiões (MIGNOLO, 2009). A descolonialidade é necessária para libertá-los e se inicia quando

[...] você percebe que sua inferioridade é uma ficção criada para dominá-lo(a), e você não quer assimilar ou aceitar resignadamente a má sorte de ter nascido igual a todos os seres humanos, mas ter perdido essa igualdade logo após ter nascido por causa do local em que você nasceu (MIGNOLO, 2013, p. 135).

Como a modernidade e a totalidade da episteme eurocêntrica atingiram todas as sociedades do mundo, segundo Mignolo (2011), torna-se necessário que "bárbaros" promovam a epistemologia da exterioridade. Essa opção descolonial deve ser proposta pelo resto do mundo, sob uma perspectiva de transmodernidade pluriversal (DUSSEL, 2002), por meio de engajamento com teorizações e pensamentos fronteiriços que foram em grande parte encobertos ou ignorados pela epistemologia da totalidade. Visto que não há uma parte externa à modernidade, que é a epistemologia da totalidade, "o pensamento fronteiriço é a epistemologia da exterioridade, isto é, do externo [que foi] gerado a partir do interno" (MIGNOLO e TLOSTANOVA, 2006, p. 206). O pensamento fronteiriço deve se originar a partir da diferença colonial, ou seja, do lócus em que modernidade e colonialidade se encontram (MIGNOLO, 2011). A pluriversalidade transmoderna transcende a modernidade eurocêntrica ao não propor a substituição desta por outra modernidade, mas, sim, a construção de um mundo em que diversos mundos e conhecimentos podem coexistir.

Segundo Mignolo (2011), o reconhecimento do quadro dominante de geopolítica do conhecimento que sustenta a colonialidade exige que mudemos o foco daquilo que é enunciado para a enunciação; para tanto, devemos nos perguntar "quem e quando, por que e onde o conhecimento é gerado" (MIGNOLO, 2009, p. 4). Enfim, por meio do reconhecimento da gestão estratégica da geopolítica do conhecimento, podemos resgatar conhecimentos que foram subalternizados e, então, descolonizar a área de gestão estratégica para "desmarginalizar" as organizações familiares.

\section{O Fundamentalismo da Gestão: Uma Análise Descolonial}

Quem poderia imaginar na Europa no início dos anos 1970 que o campo da gestão e a lógica hegemônica subjacente viessem a ser aplicados em poucas décadas ao governo, à sociedade, ao meio ambiente, ao governo, à academia ou ao conhecimento? Quem poderia imaginar naquela época que essas aplicações (não obstante o espectro de variações) seriam adotadas também na Rússia, na China, em Angola ou em Cuba? Quem poderia imaginar a aplicação quase irrestrita da "gestão" nas diversas regiões do mundo que classificavam aquela "gestão" como um campo informado por estratégias etnocêntricas ou imperialistas? 
Analistas concordam que essa extraordinária trajetória de expansão e universalização de uma história local em outras palavras, o "fundamentalismo da gestão" - foi impulsionado no contexto pós-Guerra Fria por processos de imposição da globalização neoliberal e do fundamentalismo de mercado. Sob uma perspectiva histórica que se tornou mais usual em anos recentes, em resposta a esse quadro de geopolítica do conhecimento, é correto dizer que essa hegemonia ou predominância foi iniciada no contexto da Guerra Fria com os processos de americanização em diferentes países e regiões (ver KIESER, 2004; KIPPING, ÜSDIKEN e PUIG, 2004). Sob uma perspectiva histórica menos usual, informada pela opção descolonial, é correto afirmar que essa trajetória não teria sido possível se o âmbito da "gestão" não tivesse sido elevado ao nível de "gestão científica" nos EUA no início do século passado e, em seguida, vinculado ao modelo de capitalismo gerencial e à corporação industrial moderna no contexto da Guerra Fria. Sob uma perspectiva histórica de longue durée mais ampliada, esse processo não teria sido possível sem os processos de colonialidade eurocêntrica iniciados no século XVI, quando a América foi "descoberta" pelos europeus.

A partir dos trabalhos de Frederick Taylor nos EUA - mais especificamente, com a publicação de Principles of scientific management (TAYLOR, 1911) - o âmbito da gestão iniciou uma trajetória de cientificação que, certamente, não teria sido tão exitosa em termos geoepistêmicos se tivesse ocorrido em algum país periférico. Um dos princípios fundamentais do management é a capacidade de fazer com que outras pessoas façam dentro da corporação industrial moderna o que tem de ser feito sob uma perspectiva civilizatória de neutralidade no que diz respeito tanto ao binômio capital/trabalho (SPECTOR, 2006) quanto ao binômio público/privado (MIZRUCHI, 2004). A partir da construção dessa gestão científica nos EUA e do estabelecimento dos princípios normativos que diferem a gestão daquilo que não é gestão (moderna), diferentes tipos de práticas, conhecimentos e histórias locais foram eliminados ou subalternizados por representar não conhecimento ou subconhecimento, vinculados a "tradições", "crenças" ou "culturas" de bárbaros ou primitivos. Os "diferentes" nos EUA foram, então, classificados como vinculados à "má gestão" - que deveriam, então, ser analisados, classificados e corrigidos pela "gestão científica" e pelo conhecimento correspondente. $\mathrm{O}$ fundamentalismo da gestão marginalizou as organizações familiares, primeiramente nos EUA, ao celebrar a corporação moderna industrial e a sociedade corporativa (BARLEY, 2007) e, posteriormente, no resto do mundo.

Sob a perspectiva do resto do mundo, esse processo de marginalização era mais complicado, devido ao âmbito da geopolítica do conhecimento. No resto do mundo, à "má gestão" ou a "não gestão" significavam oposição aos fundamentos civilizatórios que informavam a gestão científica construída nos EUA. Segundo o fundamentalismo da gestão (também conhecido como "movimento da gestão científica" nos EUA), a não conformidade à gestão científica poderia resultar na disseminação em escala global dos princípios de comunismo, socialismo e anarquismo que emergiam na Europa no final do século XIX, em resposta às contradições do capitalismo (MERKLE, 1980). Esse quadro de colonialidade, que ficou mais óbvio durante a Guerra Fria (COOKE, MILLS e KELLEY, 2005), reproduzia e reforçava o processo civilizatório iniciado pela modernidade eurocêntrica no final do século XV. Má gestão ou não gestão no resto do mundo podiam ser interpretadas nos EUA como manifestações de antiamericanismo; isso ajuda a explicar management como um elemento central do americanismo no Brasil e em outros países (p. ex., ALCADIPANI et al., 2012).

A modernidade eurocêntrica estabelecera de modo similar a distinção abissal entre o moderno e o não moderno (SANTOS, NUNES e MENESES, 2008). A partir dessa modernidade ou história local que se transformou em desenho global (MIGNOLO, 2011), os diferentes tipos de "não moderno" no resto do mundo foram classificados como vinculados ao barbarismo ou primitivismo. De modo similar, as ciências sociais no século XIX na Europa acabaram estabelecendo para o resto do mundo o que é política, o que é sociedade, e o que é economia e produziram teorias para a prática e avaliação desses âmbitos sob a perspectiva do eurocentrismo (WALLERSTEIN, 1997). Por meio da universalidade eurocêntrica, os diferentes tipos de conhecimentos ao redor do mundo foram eliminados, subalternizados ou reformados pelo conhecimento científico (MIGNOLO, 2011). A história se repete. No contexto da Guerra Fria, o Primeiro Mundo cria a regra e dá a si o privilégio de numerar e classificar os "demais mundos"; "como sabemos: o primeiro mundo tem conhecimento, o terceiro mundo tem cultura" (MIGNOLO, 2009, p. 1). De modo 
correspondente, o processo de cientificação da gestão nos EUA seguiu e reforçou o desenho da ciência moderna eurocêntrica. A gestão científica foi transformada, primeiramente, em um bem nacional nos EUA; em seguida, foi traduzida como bem ocidental durante a Guerra Fria; e, posteriormente, no contexto da globalização neoliberal, foi tida como bem universal.

A gestão científica ganhou um impulso extraordinário a partir da atribuição do êxito dos EUA à gestão das grandes corporações. Em 1962, no início dos Anos Dourados, Alfred Chandler Jr. - historiador que viria anos depois a ser aclamado como o pai da gestão estratégica após sua entrada em Harvard - publicou a obra Strategy and structure: chapters in the history of the great industrial enterprise. A análise histórica realizada por Chandler, publicada no contexto da Guerra Fria, mostrava que as grandes corporações industriais modernas eram o motor de crescimento dos EUA e superiores a outros tipos de organização. A superioridade das grandes corporações não era explicada por Chandler por seu poder político-econômico relativo ou por sua vinculação ao poderio militar e geopolítico dos EUA, mas, sim, pela extraordinária capacidade de adequação de suas estruturas e estratégias às demandas da sociedade e do mercado por meio da gestão.

Não foi nada surpreendente que Chandler (1962) tenha tornado-se em Harvard um dos pais da área que viria a ser denominada strategic management nos EUA. Essa área, por sua vez, liderou a estratégia de tornar a grande corporação moderna dos EUA em arquétipo de superioridade em todo o mundo (PETTIGREW, THOMAS e WHITTINGTON, 2002). A área de gestão estratégica marginalizou a dimensão da (geo)política e as concepções/teorizações centradas no Estado que eram importantes para o resto do mundo naquela época. Mais especificamente, essas dimensões e teorizações que poderiam ser úteis para a gestão estratégica no resto do mundo foram marginalizadas por estar associadas ao comunismo no contexto da Guerra Fria (KELLEY, MILLS e COOKE, 2006).

Segundo Chandler, as grandes corporações se dedicavam ao desempenho econômico de longo prazo - em oposição àqueles que argumentavam que grandes corporações detinham poderes excessivos e que isso impossibilitava a democracia de mercado nos EUA. Segundo a teoria da dependência, que era classificada como não conhecimento pela área de gestão estratégica, as grandes corporações promoviam dominação, dependência e subdesenvolvimento no Terceiro Mundo (p. ex., FURTADO, 1966).

O trabalho de Chandler se opunha, nos EUA, ao trabalho de Wright Mills - The power elite (1956) - que argumentava que os EUA eram governados por elites que ocupavam diferentes tipos de organização. Essas elites "gerenciavam" o poder político e bloqueavam a construção da democracia no país. O livro de Mills (1956) descreve o complexo relacionamento entre as elites política, militar e econômica dos EUA e mostra que os membros dessas três instituições compartilhavam uma visão de mundo baseada em quatro pontos que se opunham frontalmente ao que viria a ser defendido por Chandler: a) membros da elite compartilhavam uma definição militar da realidade; b) membros da elite se viam como superiores e separados do resto da sociedade; c) membros da elite tinham capacidade de movimentação dentro e através das três estruturas institucionais; e d) a socialização de novos membros dependia de sua capacidade de reproduzir os interesses e fundamentos dessas elites de poder. O trabalho de Chandler mostrava que as corporações modernas não eram governadas por membros da elite, mas, sim, por gerentes assalariados. A corporação industrial moderna, segundo a obra de Chandler, era controlada por gerentes, de acordo com a tese de separação entre propriedade e controle proposta por Berle e Means (1932). Essa descoberta seria enfatizada em The visible hand, outro clássico de Chandler, publicado em 1977.

Cabe destacar, ainda, que a representação de elite nos EUA era mais frequentemente associada ao governo (WEAVER e ROCKMAN, 1993) e às famílias (USEEM, 1979) pelas literaturas de sociologia e ciência política. Ademais, o capitalismo europeu era associado ao controle de famílias; por sua vez, essa estrutura era associada ao histórico de feudalismo na Europa, que ajudava a explicar as duas guerras mundiais naquele século. No resto do mundo, famílias eram associadas a estruturas autoritárias que bloqueavam o avanço da democracia (FUKUYAMA, 1995). Quando Chandler (1990) comparou o capitalismo estadunidense com o inglês, ele batizou este último de "capitalismo familiar", e o classificou como inferior ao primeiro. O passado dos EUA como colônia britânica e sua posição de hegemonia no pós-Segunda Guerra ajudam a explicar 
tanto a posição de Chandler quanto a reação de alguns acadêmicos ingleses à sua análise (FRUIN, 2009). O resto do mundo foi ignorado por Chandler; não havia estratégia ou conhecimento nesses países que pudesse ser útil para o mundo liderado pelos EUA no contexto da Guerra Fria.

Havia um problema adicional. A teoria da dependência produzida na América Latina (FURTADO, 1966), que é uma das bases da opção descolonial, apontava as corporações multinacionais do Norte como grandes responsáveis pela promoção de subdesenvolvimento no resto do mundo. Essa teorização foi interpretada no Primeiro Mundo como vinculada a interesses de elites locais ou ao imperialismo soviético. A teoria da dependência, que era importante para a construção de uma área de "estudos em estratégia" no Brasil que reconhecesse questões de geopolítica (inclusive do conhecimento), foi classificada nos EUA como "não conhecimento". Dependência significa subordinação, a ideia de que o desenvolvimento desses países está submetido (ou limitado) pelo desenvolvimento de outros países e não era forjado pela condição agrárioexportadora ou pela herança pré-capitalista dos países subdesenvolvidos, mas pelo padrão de desenvolvimento capitalista dos países do Terceiro Mundo e por sua inserção no capitalismo mundial imposta pelo imperialismo primeiro-mundista. A superação do subdesenvolvimento passaria pela ruptura com a dependência e não pela modernização e industrialização da economia, o que pode implicar, inclusive, a ruptura com o próprio capitalismo (DOS SANTOS, 1970). Mais adiante, a teoria da dependência foi, então, associada a processos envolvendo "famílias" no Terceiro Mundo que se beneficiavam da resistência à modernização e ao desenvolvimento. O estudo desenvolvido por Peter Evans (1979) ressalta o poder de elites locais em processos de colonização, por meio de alianças envolvendo estado e corporações que lhes garantiriam a manutenção do poder. Por sua vez, outras versões da própria teoria da dependência que enfatizavam as elites locais, ao invés do imperialismo, como principal obstáculo para países do Terceiro Mundo, foram reconhecidas e publicadas nos EUA. Ademais, análises críticas à ingenuidade ou à politicização da teoria e aos riscos para a ordem mundial foram publicadas nos EUA, com base no argumento de que a teoria da dependência

[...] bem mais do que a associação intelectual do marxismo e o nacionalismo do sul. Representa também um esforço prático para a concreta unificação de duas das forças históricas mais importantes do século, com possíveis significativas consequências tanto para a história local quanto para a global (SMITH, 1979, p. 248).

O maior alcance obtido por esses estudos, comparado ao alcance obtido pelo estudo de Furtado (1966), inclusive no Brasil, ilustra o funcionamento da gestão estratégica da geopolítica do conhecimento por meio da diferença colonial (WANDERLEY e FARIA, 2012).

A área de gestão estratégica teve, então, um papel central na marginalização colonialista do conceito de organizações familiares e, em termos mais amplos, a supressão do capitalismo familiar e de alternativas de capitalismo e alternativas ao capitalismo que pudessem ser produzidas no resto do mundo. Por meio do questionável pressuposto de que as grandes corporações modernas e as boas teorias que informam a área de gestão estratégica são benéficas até para os EUA (ver GOSHAL, 2005; BARLEY, 2007), o fundamentalismo da gestão reforçou em escala global o divórcio ideológico, geoepistêmico e civilizatório entre família e moderno. Esse movimento de colonialidade epistêmica, catalizado pelo quadro da Guerra Fria, restringiu as agendas de acadêmicos da América Latina. Conhecimentos que se referissem a "capitalismo familiar" ou a alternativa ao capitalismo por meio de organizações familiares foram classificados como subconhecimento ou não conhecimento. A área de gestão estratégica foi implantada nas escolas de administração do Brasil exatamente para promover a profissionalização/modernização das organizações no país, sendo a reforma das empresas familiares um dos principais focos (BERTERO, VASCONCELOS e BINDER, 2003).

Apesar da teoria da dependência tornar óbvia a geopolítica (incluindo a do conhecimento) e a necessidade de desprendimento dos cânones fundamentalistas/colonialistas do conhecimento dominante, o âmbito da gestão estratégica da geopolítica do conhecimento não foi contemplado pela área de gestão estratégica no Brasil ou em outros países do Terceiro Mundo. Análises em gestão estratégica ficaram circunscritas ao domínio da organização produtiva e dominadas por teorizações econômicas vinculadas à grande corporação industrial 
moderna. Teorizações de política e de geopolítica para a análise de estratégias das grandes corporações tornaram-se virtualmente inexistentes. Esse quadro de fundamentalismo da gestão ajuda a explicar tanto a virtual ausência de "empresas familiares" na literatura de strategic management não apenas nos EUA, mas, também, no resto do mundo.

\section{O Fundamentalismo no Contexto da Guerra Fria}

Descolonizar o fundamentalismo da gestão a partir do resto do mundo (e da diferença colonial) é um passo importante para que organizações familiares ocupem seu devido lugar na literatura e na sociedade. Segundo a opção descolonial, o fundamentalismo da gestão que informa a marginalização das organizações familiares não se restringe à Guerra Fria como um período fixo. Uma das fontes de confusão enfrentadas por pesquisadores no resto do mundo nesse sentido é o crescente número de análises históricas baseadas na concepção de americanização e Guerra Fria como períodos fixos, em detrimento da perspectiva de longue durée que caracteriza a modernidade/colonialidade, em resposta ao apogeu do fundamentalismo da gestão, liderado pelos EUA, com o fim da Guerra Fria. Processos descritos na literatura produzida no Norte como "americanização" e tidos como típicos do contexto da Guerra Fria acabaram reforçando o fundamentalismo da gestão (p. ex., KIESER, 2004).

A americanização foi reinventada no pós-Guerra Fria após a vitória final do neoliberalismo ocidental, liderado pelos EUA, como única superpotência. No pós-Guerra Fria o Ocidentalismo passa a ser liderado/dominado pelos EUA. Americanismo é, então, definido neste artigo como "o crescimento da dominação militar, econômica, financeira e cultural dos EUA, que desde 1990 se autoproclamou como única" (MENNELL, 2010, p. 554). Americanismo, assim como globalismo (STEGER, 2009), é análogo à transformação da "globalização" em neoliberalismo neoimperial e à ascensão de um regime de "dominação sem hegemonia" (ARRIGHI, 2007). A globalização ocidental é tida, neste artigo, como sinônimo de americanização e ocidentalização. Segundo a opção descolonial, esses diferentes termos estão interconectados no tempo e no espaço, por meio da diferença colonial.

Em outras palavras, americanização na Guerra Fria e americanização ou americanismo no pós-Guerra Fria são descritos neste artigo como diferentes versões do Ocidentalismo. Ocidentalismo é definido como

[...] o conjunto de práticas representacionais que propicia a produção de concepções de mundo, que 1) separa os componentes globais em unidades compostas; 2) desagrega suas relações históricas; 3) transforma diferença em hierarquia; 4) naturaliza essas representações; e, consequentemente, 5) intervém, apesar de involuntariamente, na reprodução de prevalecentes relações de poder assimétricas (CORONIL, 1996, p. 57).

A literatura descolonial ressalta que não é possível dissociar o conceito de americanidade do conceito de modernidade: "americanidade sempre foi, e permanece até os dias de hoje, um elemento essencial do que significa modernidade" (QUIJANO e WALLERSTEIN, 1992, p. 549). A opção descolonial possibilita, então, o reconhecimento de que a marginalização de organizações ou grupos familiares não é um fenômeno relacionado somente ao fundamentalismo da gestão que se inicia com a ascensão científica da gestão nos EUA. O fundamentalismo da gestão em si se refere à gestão da ordem a partir da modernidade sob uma perspectiva da longa duração. O fundamentalismo modernista ou eurocêntrico, mobilizado pelas ciências sociais na Europa, prescrevia a substituição de sociedades tradicionais, em geral comandadas por famílias constituídas por "selvagens não modernos" ou "bárbaros", pela sociedade moderna (GIDDENS, 1993).

$\mathrm{Na}$ área de economia, as relações sociais e os laços familiares eram descritos como uma barreira à introdução da modernidade (MOORE, 1997) e à própria civilização (MOUSSEAU, 2003). No contexto da Guerra Fria, laços familiares eram descritos como traços de autoritarismo e facilitadores da introdução do comunismo no 
Terceiro Mundo. Os bárbaros e selvagens foram substituídos por "comunistas" ou "socialistas" pela americanidade na Guerra Fria, assim como o eurocentrismo foi substituído pelo americanismo.

Organizações ou grupos familiares foram associados não mais a barbarismo, mas, sim, a comunismo pela teoria da modernização liderada pelos EUA. Na teoria dos cinco estágios de desenvolvimento proposta por Rostow (1960) - uma das principais doutrinas anticomunistas construídas nos EUA no ápice do contexto da Guerra Fria e que se transformou na principal teoria de desenvolvimento do Primeiro Mundo para o Terceiro Mundo - a sociedade tradicional composta por famílias protagonizava a primeira etapa e representava o oposto ao modelo de desenvolvimento e modernização simbolizado pela sociedade estadunidense. A teoria de modernização destaca os obstáculos internos ao desenvolvimento em países do Terceiro Mundo. Tais obstáculos são relacionados ao atraso ou tradicionalismo das pessoas. Um dos conceitos centrais é o "familismo" (ROSTOW, 1960; INKELES, 1983), que afirma que lealdades familiares sufocam interesses individuais e restringem a capacidade dos indivíduos de alcançar objetivos familiares, porque desejos e necessidades pessoais acabam ficando subservientes aos da família. Em outras palavras, o círculo de interesse e confiança acaba sendo limitado pelos laços de parentesco.

Esse traço do fundamentalismo inaugurado com a modernidade eurocêntrica não foi alterado após o suposto fim da Guerra Fria e a ascensão da globalização neoliberal - ou neoimperialismo neoliberal, como descrito por autores que são ignorados pela área de gestão estratégica. No contexto pós-Guerra Fria, relações e organizações familiares continuaram sendo associadas a questões negativas como nepotismo, corrupção e estagnação (p. ex., FUKUYAMA, 1995), não apenas pelo próprio proponente da tese de fim da história (FUKUYAMA, 1992), mas, também, por outros cientistas sociais e autoridades que argumentavam que organizações familiares não se adequam ao fundamentalismo de mercado mobilizado pela globalização neoliberal e pelos mecanismos correspondentes mobilizados pelo Consenso de Washington (BLOCK, 2011).

A partir de uma perspectiva descolonial, tendo em vista as seguidas crises da globalização neoliberal e a ascensão das economias emergentes - para a qual as organizações familiares continuam cumprindo um papel estratégico -, a questão crucial é analisar como e por que o status disciplinador do conhecimento de administração-gestão produzido nos EUA tornou-se aceito tanto no Norte quanto no Sul como "verdades objetivas e universais para a organização de relações de trabalho" (JACQUES, 1996, p. xiii). Mais especificamente, é importante compreender como a gestão estratégica da geopolítica do conhecimento funciona no campo da gestão.

Análises históricas produzidas no Norte mostram que as disciplinas da gestão foram influenciadas pelo americanismo no contexto da Guerra Fria e que isso tanto impulsionou como restringiu o desenvolvimento do campo (COOKE, MILLS e KELLEY, 2005; KELLEY, MILLS e COOKE, 2006; MCLAREN e MILLS, 2008). Nessa época foi construída a representação de "gestor ideal", que se caracterizava como "um homem educado que assumia sua autoridade e aceitava responsabilidade social" (MCLAREN e MILLS, 2008, p. 386), não apenas se aproxima da descrição feita por Chandler (1977) para o visible hand da corporação industrial moderna, que ajudou a subalternizar as empresas familiares. Cummings e Wilson (2003) argumentam que a estrutura hierárquica triangular proposta por Chandler (1962) para representar a corporação moderna e a gestão made in US reproduzia a descrição feita pelos influentes relatórios sobre as escolas de negócios desenvolvidos pelas fundações Ford e Carnegie. Especialmente após a revolução cubana, essas fundações "científicas" tiveram papel central na gestão estratégica da geopolítica do conhecimento da gestão e no reforço do fundamentalismo da gestão em países do Terceiro Mundo - em especial na América Latina - por meio de processos que elas mesmas denominavam americanização (ver PARMAR, 2002).

As fundações acadêmicas tiveram papel central não apenas na difusão do conhecimento made in $U S$ informado pelos processos de americanização, mas, também, na imposição do fundamentalismo da gestão por meio da organização das instituições acadêmicas locais no Terceiro Mundo (GUEDES e FARIA, 2010). A gestão estratégica da geopolítica do conhecimento pelas fundações era informada pela universalidade eurocêntrica (PARMAR, 2002). Um dos propósitos centrais de tais processos é suprimir o interesse dos pesquisadores com a gestão estratégica da geopolítica do conhecimento. 
Entretanto, análises históricas produzidas no Norte ressaltam que a construção de "gestão estratégica" e da representação do "gestor ideal" se dá em um contexto histórico em que os EUA podiam impor o seu próprio "sistema cultural [...] como uma estrutura objetiva, neutra e universal na qual todos os demais artefatos culturais poderiam ser sublimados" (JACQUES, 1996, p. xv). Após o fim da $2^{\mathrm{a}}$ Guerra Mundial, as duas grandes potências nucleares, EUA e URSS, impuseram uma divisão ideológica que anulou a noção de mundos (no plural). A Guerra Fria representa uma "guerra entre diferentes versões de modernização" (COOKE, MILLS e KELLEY, 2005, p. 10) que ajudou a suprimir alternativas. Curiosamente, na revolução comunista da China, as famílias foram transformadas em um dos principais alvos pelas novas autoridades (HELISTROM, 1962). É correto afirmar que, assim como a americanidade representa a continuidade da modernidade eurocêntrica, a Guerra Fria em si não representa uma descontinuidade histórica. Assim como a americanização da Guerra Fria representa a americanidade como modernidade, o fundamentalismo da gestão representa a continuidade do fundamentalismo da modernidade eurocêntrica ou Eurocentrismo/Ocidentalismo (GROSFOGUEL, 2012a; 2012b).

A partir de uma perspectiva descolonial, entendemos que esse processo ocorreu em detrimento de instituições (tanto no Norte quanto no Sul) que concebiam, teorizavam e praticavam estratégia e gestão a partir de "outras" perspectivas. Em outras palavras, suprimiu teorias de fronteira e descolonização que poderia ter ocorrido, por exemplo, por meio do engajamento com os fundamentos da teoria da dependência e com a teologia da libertação. Dentre essas possibilidades suprimidas pela gestão estratégica made in US destacamos não apenas a impossibilidade de termos desenvolvido estratégia no Brasil sob uma perspectiva de pluriversalidade ao invés de subordinada ao strategic management, mas, em especial, a gestão (estratégica) praticada por organizações familiares e a (re)organização do conhecimento correspondente. Em outras palavras, este foi marginalizado ou classificado unilateralmente como não conhecimento pelos contextos de organização do conhecimento de gestão subordinados ao fundamentalismo da gestão.

Esse quadro afetou o conhecimento da gestão em vários países do Terceiro Mundo, em especial na América Latina. É correto afirmar que isso aconteceu não apenas em países da América Latina, mas, também, nos EUA (ver PERROW, 2002). A literatura ressalta que colonialidade afeta tanto o colonizador quanto o colonizado (MIGNOLO, 2011). O processo de colonização epistêmica nos EUA em termos mais específicos e no Ocidente de forma mais ampla justifica a construção de análises histórico-descoloniais a partir do resto do mundo para ajudar a promover a descolonização da gestão (MIGNOLO, 2009). O efeito da colonialidade (ou seja, o fundamentalismo da gestão sob uma perspectiva de longa duração) é tão intenso nos EUA que análises históricas conduzidas por pesquisadores daquele país apontam que a revolução gerencial atribuída por Chandler (1962) exclusivamente às grandes corporações ocorreu também no âmbito do governo dos EUA (FERLEGER e LAZONICK, 1993).

Porém, a importância (geo)política da dicotomia estado/mercado na academia de gestão no contexto da Guerra Fria, a marginalização de organizações familiares por estar associadas não somente a tipos inferiores de capitalismo, mas, também, a falhas de governo, e os projetos de projeção internacional do capitalismo gerencial ajudam a explicar por que um dos pais da gestão estratégica nos EUA foi incapaz de reconhecer que organizações governamentais daquele país praticavam a "boa gestão" no âmbito do governo (e da agricultura, ao invés da indústria). Esse mesmo movimento que privilegiou as grandes empresas geridas pela visible hand (CHANDLER, 1977) que caracteriza o capitalismo gerencial e que considera o estado fora do escopo de análise (CHANDLER, 1962), acabou por rotular como inferior o "capitalismo familiar" e subalternizou os estudos e pesquisas, tanto nos EUA como no resto do mundo, sobre organizações familiares. Esse quadro permanece no contexto pós Guerra Fria. Em termos de geopolítica e geoeconomia, a diferença central é a ascensão do resto do mundo e as seguidas crises da ordem neoliberal ocidental, liderada pelos EUA. Em termos de geopolítica do conhecimento, esse quadro é adicionado pela ascensão da opção descolonial. 


\section{Repensando Estrategicamente Organizações Familiares}

A queda do muro de Berlim ainda significa, para muitos autores, o fim da Guerra Fria e o "fim da história" no que diz respeito às disputas entre Ocidente e não Ocidente. Por outro lado, nos dias atuais, é crescente o número dos que entendem que esse evento acelerou a expansão da globalização neoliberal ocidental liderada pelos EUA como superpotência solitária em direção ao resto do mundo. De fato, alguns autores argumentavam que globalização é um eufemismo para (neo)imperialismo ou (neo)colonialismo. Estes foram classificados como não autores ou subautores de não conhecimento ou subconhecimento, apesar de sua central importância para a compreensão do quadro contemporâneo. Isso ajuda a explicar por que as análises históricas focadas na Guerra Fria e nos processos de americanização não abraçaram a opção descolonial.

O conhecimento eurocêntrico que informa o fundamentalismo da gestão afirma que a globalização representa o estágio mais elevado da humanidade - ou seja, do Eurocentrismo (GIDDENS, 1994) - e nem reconhece que a globalização ocidental convive com a globalização oriental (PIETERSE e PETERS, 2012), materializada pela ascensão (ou retorno) das economias emergentes na Ásia.

Com base no argumento descolonial de que o pós-Guerra Fria representa um estágio mais agudo do Ocidentalismo americanista, é correto afirmar que ao fortalecimento do fundamentalismo da gestão é um dos principais elementos para a ascensão do neoimperialismo neoliberal (STEGER e ROY, 2010). A hegemonia dos EUA em gestão tornou-se muito mais sofisticada e problemática para o resto do mundo do que no período da Guerra Fria.

O fundamentalismo da gestão deve ser visto, sob uma perspectiva de longa duração, como um processo eurocêntrico de construção de uma cultura ocidental global. Sob essa perspectiva, essa cultura global não deve ser entendida como uma cultura global acadêmica. Esse importante processo de Ocidentalismo americanista não vem sendo conduzido somente por acadêmicos e instituições acadêmicas. A gestão estratégica da geopolítica do conhecimento no campo da gestão envolve um número bem mais amplo de atores, instituições e países. $O$ privilégio concedido à academia na produção e disseminação de conhecimento válido foi rompido no pós-Guerra Fria. Por meio de um processo de socialização ou neoliberalização da academia em escala global, a academia foi transformada em apenas um dos responsáveis pela colonialidade via gestão.

O processo de construção de uma cultura global em gestão informada pelo Ocidentalismo americanista tem sido conduzido por diferentes tipos de atores e organizações, tais como grandes empresas de consultoria, grandes corporações, think tanks, organizações não governamentais, organizações governamentais, e outros agentes e instituições que, de uma forma ou de outra, "governam" a ciência (LATOUR, 1987; LOCKE, 1996). Esse quadro de governança ficou mais crítico após os eventos de 11 de setembro. A gestão estratégica continua sendo liderada pelo mundo euro-americano (MURPHY e ZHU, 2012), mas sua constituição envolve uma comunidade transnacional do Norte e do Sul.

No período que se estende desde o fim da $2^{\mathrm{a}}$ Guerra Mundial até o (suposto) fim da Guerra Fria, a gestão estratégica da geopolítica do conhecimento nesse campo ganhou uma nova escala. A Academy of Management (que é estadunidense, mas não se descreve assim, por se considerar universal ou "global"), por exemplo, teve papel central para a universalização do conhecimento da área durante o período de sua formação (1936-1960) (GRANT e MILLS, 2006). A hegemonia dos EUA nesse campo, sob uma perspectiva ampliada de geopolítica do conhecimento, não era tão preocupante para a Europa e para o resto do mundo como nos dias atuais. Em grande parte, os temores quanto aos avanços do império soviético tornavam menos problemática a hegemonia dos EUA em um campo que era tido como etnocêntrico e de baixa respeitabilidade acadêmica. A gestão estratégica da geopolítica do conhecimento em gestão passa a interessar a um número mais amplo de instituições, pessoas e países a partir do momento em que a globalização neoliberal liderada pelos EUA foi traduzida como fim da história e a simultaneidade de processos de integração e desintegração cultural (FEATHERSTONE, 1990), de convergência e divergência (SPICER, 2006) com o (suposto) fim da Guerra Fria, e as seguidas crises da ordem neoliberal e ascensão do 
resto do mundo (lideradas pelas economias emergentes) (ARRIGHI, 2007) elevaram sobremaneira a importância da "gestão estratégica" das tensões entre o Ocidente (liderado pelos EUA como "hiperpotência", especialmente após a ascensão do unilateralismo em decorrência dos eventos de 11 de setembro) e o resto do mundo.

Especialmente no que diz respeito às economias emergentes, a "administração" das tensões por meio da gestão estratégica da geopolítica do conhecimento ganhou um impulso que inexistia no contexto da Guerra Fria. No Brasil, por exemplo, a expansão do campo a partir do início dos anos 1990, liderada pelo fundamentalismo da gestão, foi extraordinária. Como era de se esperar, emergiram manifestações de resistência ao fundamentalismo da gestão liderado pelos EUA. A partir do final dos anos 1990, em paralelo aos primeiros sinais de fracasso do Consenso de Washington e ao processo de acelerada expansão da academia local de gestão, em grande parte impulsionada por fatores exógenos vinculados ao fundamentalismo da gestão que ajudavam a gerenciar as crises e contradições da globalização neoliberal, mesmo em gestão estratégica alguns pesquisadores ousaram criticar a importação de conhecimento produzido nos EUA (p. ex., BERTERO, VASCONCELOS e BINDER, 2003). Tendo o conhecimento mainstream e o "eixo" anglo-americano como principais alvos, autores já haviam argumentado no Brasil que pesquisadores deveriam produzir conhecimento que fizesse sentido para o contexto local ao invés de reproduzir o conhecimento produzido no "estrangeiro" (RODRIGUES e CARRIERI, 2001; MOTTA e CALDAS, 1997).

Outras análises que criticam o descasamento entre a literatura importada de gestão estratégica e a realidade no Brasil (p. ex., BIGNETTI e PAIVA, 2001) seguiram, assim como no Norte (p. ex., GRANDY e MILLS, 2004; CLEGG, CARTER e KORNBERGER, 2004). Entretanto, essas críticas não mencionam (ou as que mencionam não conseguiram ter a necessária ênfase) a marginalização da organização familiar. Ou seja, a marginalização das organizações familiares continua em vigor na área de gestão estratégica também no Brasil, não obstante o cada vez mais evidente ocaso do fundamentalismo da gestão - ilustrado pelas seguidas crises da ordem neoliberal ocidental e a correspondente ascensão das economias emergentes - e a importância estratégica desse tipo de organização para o país e outras economias emergentes.

Nos primeiros momentos do neoliberalismo, orientado para reestabelecer a hegemonia dos EUA que começou a erodir nos anos 1970 (HARVEY, 2003), a área de gestão estratégica imediatamente reforçou sua subordinação ao economicismo neoliberal (CLEGG et al., 2011; PETTIGREW, THOMAS e WHITTINGTON, 2002) para viabilizar a expansão irrestrita da ordem da "gestão" e para reforçar a subalternização de teorizações vinculadas à opção descolonial por meio da ideia de que estamos todos vivendo um borderless world que supostamente representa o fim da história iniciada pela modernidade eurocêntrica e finalizada pelos EUA (FUKUYAMA, 1992).

Tendo em vista as origens geopolíticas do fundamentalismo da gestão e a colonialidade correspondente, é possível argumentar, então, que essa ausência está relacionada não apenas à longa duração da colonialidade eurocêntrica, mas, também, à ascensão do unilateralismo dos EUA e à correspondente militarização da globalização neoliberal e do neoimperialismo neoliberal a partir das seguidas crises da globalização neoliberal, liderada pelos EUA, e pela ascensão do unilateralismo dos EUA após os eventos de 11 de setembro (STEGER, 2009; STEGER e ROY, 2010). A guerra global ao terror imposta pelos estrategistas da administração de George W. Bush passou a descrever as organizações familiares no "resto do mundo" como um dos focos de ameaça à civilização ocidental (p. ex., DE GOEDE, 2008). Os vínculos a sistemas amplos e relações de parentesco no mundo não ocidental - ou seja, o "familismo" - que vêm sendo historicamente interpretados pelo Ocidente como uma das principais causas de resistência dos árabes (um dos principais constituintes da chamada "mente árabe") ao desenvolvimento/modernização e, em consequência, à democratização, voltaram a ser um foco de atenção na literatura do Ocidente. Após os eventos de 11 de setembro, juntamente com a ascensão do "neobarbarismo", familismo passou a ser associado não apenas à "mente árabe", mas ao terrorismo: "Rótulos de 'terrorismo' e 'familismo' ou 'mente árabe' servem como poderosas invenções que legitimam a continuação de projetos coloniais econômicos ou políticos. Os 
imaginários do atraso do 'terrorismo' e da 'mente árabe' estão intimamente ligados” (TUASTAD, 2003, p. 592).

Por meio da opção descolonial, argumentamos que a ausência desse tipo de marginalização nas críticas sobre gestão estratégica que vêm sendo produzidas no Norte é explicada por questões de geopolítica do conhecimento que foram negadas pela área. É necessário que o resto do mundo proponha a construção de uma área em estratégia, como ilustrado por este artigo, que reconheça a gestão estratégica da geopolítica do conhecimento em gestão vinculada à opção descolonial. Autores no Brasil têm argumentado que o conhecimento produzido nos EUA não é adequado à realidade local devido a especificidades culturais ou institucionais (p. ex., BERTERO et al, 2003), em detrimento de questões referentes à gestão estratégica de geopolítica do conhecimento. Além disso, cabe destacar que desenvolvimentos acadêmicos de resistência no resto do mundo são classificados como "normais" nos EUA por três razões vinculadas a mecanismos de gestão estratégica da geopolítica do conhecimento. A primeira é que é sabido que pesquisadores no resto do mundo são produtores de subconhecimento, não conhecimento ou simplesmente "cultura". A segunda é a certeza de que a hegemonia dos EUA na academia sempre será acompanhada de manifestações e sentimentos de ressentimento por parte de acadêmicos do "resto do mundo" (NYE, 2004). A terceira é que é sabido que processos de formação de "cultura global" envolvem tanto a imposição de homogeneidade quanto a gestão da heterogeneidade por meio de processos assimétricos de hibridização (BANERJEE e LINSTEAD, 2001) que caracterizam o que denominamos neste artigo "gestão estratégica da geopolítica do conhecimento".

Esses fatores ajudam a explicar o extraordinário fortalecimento das subáreas "internacionais" do conhecimento em gestão nos EUA em décadas recentes, em especial gestão internacional, negócios internacionais e gestão estratégica internacional, e sua difusão para o resto do mundo como se fossem "universais" (GUEDES e FARIA, 2010). Em outras palavras, em termos de geopolítica do conhecimento, as manifestações locais de resistência acabam sendo úteis tanto para fortalecer e justificar processos de imposição como para fomentar e legitimar processos assimétricos de incorporação de dimensões culturais ou institucionais locais pela literatura mainstream. Tais processos ilustram a importância de análises que contemplem os contextos de (re)organização do conhecimento da gestão.

A arrogância do eurocentrismo que informa a gestão estratégica da geopolítica do conhecimento ajuda a explicar a ascensão de uma agenda focada na construção de uma "teoria de gestão estratégica da firma familiar" (CHRISMAN, CHUA e SHARMA, 2005) em/para economias emergentes. Com base no influente trabalho de Kuhn (1970) sobre paradigmas e evolução do conhecimento acadêmico (o qual ignora mecanismos e estruturas de geopolítica do conhecimento), autores argumentam que chegamos a um consenso sobre a importância de family business e que a questão central é como introduzir e enquadrar a "família" na teoria (ALDRICH e CLIFF, 2003; MOORE, 2009). Esse processo de inclusão unilateral (ou "desmarginalização" colonialista) contradiz a opção descolonial é, em grande parte, explicado pela associação de familismo a terrorismo e pelo neobarbarismo e pela dominação correspondente dos principais mecanismos de gestão estratégica da geopolítica do conhecimento em gestão pelo fundamentalismo da gestão.

\section{Tentando um "Fechamento"}

Por meio da opção descolonial, propusemos o engajamento do resto do mundo com o âmbito de gestão estratégica da geopolítica do conhecimento em gestão. Analisamos a trajetória de marginalização das organizações familiares no campo da gestão e, em particular, na área de gestão estratégica pelo fundamentalismo da gestão. Por meio de uma perspectiva histórica de longa duração, mostramos que o fundamentalismo da gestão inaugurado e imposto no contexto da Guerra Fria reforça e reproduz os fundamentos da modernidade eurocêntrica ou Ocidentalismo e fomenta a hegemonia da corporação industrial moderna em detrimento de alternativas, como, por exemplo, o das organizações familiares. 
Enquanto no Norte Chandler (1962) afirmava que as grandes empresas representavam o motor do desenvolvimento dos EUA, a teoria da dependência na América Latina - reforçando a proposta de descolonização inaugurada pela Conferência de Bandung em 1955 - sugeria que as grandes corporações estadunidenses impediam o desenvolvimento no resto do mundo e promoviam a dependência. $\mathrm{O}$ contexto de gestão estratégica da geopolítica do conhecimento em gestão ajuda a explicar como e por que Chandler tornou-se um dos pais da gestão estratégica e Furtado não foi reconhecido nem pela área de gestão estratégica no Brasil.

A expansão do capitalismo gerencial como pensamento único ocorreu em detrimento do "capitalismo familiar", classificado como inferior no Primeiro Mundo e como vinculado a subdesenvolvimento, comunismo ou barbarismo no Terceiro Mundo. Para que essa expansão fosse possível dentro de um aspecto de "neutralidade", foi necessário defender a separação de propriedade e capital e da gestão da empresa não pela família, mas, sim, pelo visible hand. $\mathrm{O}$ artigo mostra que esse processo não foi interrompido com o suposto fim da Guerra Fria. Esse processo ficou mais sofisticado e complexo a partir da expansão do fundamentalismo da gestão, vinculado no pós-Guerra Fria à ascensão do Ocidentalismo americanista.

O crescente temor de que economias emergentes venham a estabelecer uma ordem contrária aos interesses dos EUA ajuda a explicar a resiliência do fundamentalismo da gestão e, em particular, a "desmarginalização" colonialista das organizações familiares pela área de gestão estratégica em anos recentes.. Isso ajuda a explicar por que os movimentos de resistência acadêmica no Brasil em gestão e gestão estratégica não alcançaram o esperado impacto. As organizações preteridas pelo Ocidentalismo americanista - em especial as organizações familiares e as organizações governamentais - continuam exercendo um papel estratégico para o país. Organizações familiares têm sido associadas à ascensão de diversos países do resto do mundo e, em especial, à ascensão da China e à construção do modelo chinês de gestão e de desenvolvimento. $\mathrm{O}$ acirramento de mecanismos de dominação na gestão estratégica da geopolítica do conhecimento ajuda a explicar a ascensão e difusão de conhecimento sobre geopolítica do conhecimento no resto do mundo e, também, nosso engajamento na opção descolonial.

A representação dominante da globalização como mundo sem fronteiras que informa o fundamentalismo da gestão não apenas ajuda a tornar invisível o conhecimento que representa a globalização como neoimperialismo ou neocolonialismo como, também, a inibir a emergência e o fortalecimento de teorizações acadêmicas descoloniais que reconheçam a gestão estratégica da geopolítica do conhecimento.

Há inúmeras evidências de que a área de gestão estratégica enfrenta uma séria crise de legitimidade. Os escândalos em meados da década passada e a deflagração da crise da ordem neoliberal em 2008 (ou, para alguns, o início do ocaso agonizante dessa doutrina e o apogeu do regime de "dominação sem hegemonia") colocam em questão a "naturalidade" do processo continuado de transferência de conhecimento acadêmico desde os EUA para o resto do mundo. Por sua vez, o êxito alcançado por outros tipos de capitalismo e a crescente importância de organizações familiares para a ascensão de economias emergentes e a construção de alternativas à ordem neoliberal ocidental (ver WALSH, 2010) sugere que é necessária uma área de estudos de estratégia no resto do mundo que reconheça e abrace a gestão estratégica da geopolítica do conhecimento.

Neste artigo, almejamos descolonizar a área de gestão estratégica - mais especificamente, por meio de uma área de "estudos em estratégia" que reconheça a gestão estratégica da geopolítica do conhecimento em gestão - com o objetivo de desmarginalizar "estrategicamente" as organizações familiares, em resposta à "desmarginalização" colonizadora recentemente imposta pela área de gestão estratégica. Ao reconhecer o quadro dominante da geopolítica do conhecimento em gestão, esperamos que este artigo ajude a promover o engajamento de acadêmicos e instituições de diferentes partes do mundo na proposta de transmodernidade pluriversal. Ou seja, não estamos, aqui, propondo a substituição de uma modernidade por outra ou um fundamentalismo da gestão por outro, mas, sim, reforçando a proposta de construção de um mundo no qual diversos mundos e conhecimentos podem coexistir. 


\section{Referências}

ALCADIPANI, R. et al. Southern voices in management and organization knowledge. Organization, v. 19, n. 2, p. 131-143, 2012.

ALDRICH, H.; CLIFF, J. The pervasive effects of family on entrepreneurship: toward a family embeddedness perspective. Journal of Business Venturing, v. 18, n. 5, p. 573-596, 2003.

ARRIGHI, G. Adam Smith in Beijing. New York: Verso, 2007.

BANERJEE, S.; LINSTEAD, S. Globalization, multiculturalism and other fictions: colonialism for the new millenium? Organization, v. 8, n. 4, p. 683-722, 2001.

BARLEY, S. Corporations, democracy, and the public good. Journal of Management Inquiry, v. 16, n. 3, p. 201-215, 2007.

BERLE, A.; MEANS, G. The modern corporation and private property. New Jersey: Transaction, 1932.

BERTERO, C.; VASCONCELOS, F.; BINDER, M. Estratégia empresarial: a produção científica brasileira entre 1991 e 2002. Revista de Administração de Empresas, v. 43, n. 4, p. 48-62, 2003.

BIGNETTI, L.; PAIVA, E. Ora (direis) ouvir estrelas! Estudo das citações de autores de estratégia na produção acadêmica brasileira. Revista de Administração Contemporânea, v. 6, n. 1, p. 105-125, 2002.

BLOCK, F. Contesting markets all the way down. Journal of Australian Political Economy, v. 68, p. $27-42,2011$.

CHANDLER, A. D. Strategy and structure: chapters in the history of the American industrial enterprise. Cambridge, MA: MIT Press, 1962.

Press, 1977.

The visible hand: the managerial revolution in American business. Cambridge, MA: Harvard University

Scale and scope: the dynamics of industrial capitalism. In: MCCRAW, T. K.; CHANDLER, A. (Ed.). Ensaios para uma teoria histórica da grande empresa. Rio de Janeiro: Ed. FGV, 1990. p. 119-140.

CHRISMAN, J.; CHUA, J.; SHARMA, P. Trends and directions in the development of a strategic management theory of the family firm. Entrepreneurship Theory and Practice, v. 29, p. 555-575, 2005.

CLEGG, S. et al. Strategy theory and practice. London: Sage. 2011.

.; CARTER, C.; KORNBERGER, M. A "máquina estratégica": fundamentos epistemológicos e desenvolvimentos em curso. Revista de Administração de Empresas, v. 44, n. 4, p. 21-31, 2004.

COOKE, B.; FARIA, A. Desenvolvimento, administração e imperialismo do Atlântico Norte: para Eduardo Ibarra Colado. Cad. EBAPE.BR, v. 11, n. 2, editorial, 2013.

; MILLS, A.; KELLEY, E. Situating Maslow in Cold War America: a recontextualizaiton of management theory. Group and Organization Management, v. 30, n. 2, p. 129-152, 2005.

CORONIL, F. Beyond occidentalism: toward nonimperial geohistorical categories. Cultural Anthropology, v. 11, n. 1, p. 51-87, 1996.

CUMMINGS, S.; WILSON, D. Images of strategy. In: CUMMINGS, S.; WILSON, D. (Ed.). Images of strategy. Oxford: Blackwell, 2003. p. 1-40.

DE GOEDE, M. The politics of preemption and the war on terror in Europe. European Journal of International Relations, v. 14, n. 1, p. 161-185, 2008. 
DE GRAAF, N.; VAN APELDOORN, B. Varieties of US post-cold war imperialism: anatomy of a failed hegemonic project and the future of US geopolitics. Critical Sociology, v. 37, n. 4, p. 403-427, 2011.

DOS SANTOS, T. The structure of dependence. The American Economic Review, p. 231-236, 1970.

DUSSEL, E. 1492. O encobrimento do outro: a origem do mito da modernidade. Petrópolis, RJ: Vozes, 1993. World-system and "trans"-modernity. Neplanta, v. 3. n. 2, p. 221-244, 2002.

ESCOBAR, A. Worlds and knowledge otherwise: the Latin American modernity/coloniality research program. Cultural Studies, v. 21, n. 2/3, p. 179-210, 2007.

EVANS, P. Dependent development: the alliance of multinational, State and local capital in Brazil. New Jersey: Princeton University Press, 1979.

FEATHERSTONE, M. Cultura global: nacionalismo, globalização e modernidade. Rio de Janeiro: Vozes, 1990.

FERLEGER, L.; LAZONICK, L. The managerial revolution and the developmental State: the case of U. S. agriculture. Business and Economic History, v. 22, n. 2, p. 67-98, 1993.

FRUIN, W. Globalization and Alfred D. Chandler's modern (American) firm: an essay. Journal of Management History, v. 15, n. 3, p. 261-271, 2009.

FUKUYAMA, F. The end of history and the last man. New York: Free Press, 1992. Social capital and the global economy. Foreign Affairs, v. 75, n. 4, p. 89-103, 1995

FURTADO, C. U. S. hegemony and the future of Latin America. The World Today, v. 22, n. 9, p. 375-385, 1966.

GIDDENS, A. Sociology. 2. ed. London: Polity Press, 1993.

Beyond left and right: the future of radical politics. Stanford: Stanford University Press, 1994.

GOSHAL, S. Bad management theories are destroying good management practices. Academy of Management Learning and Education, v. 4, n. 1, p. 75-91, 2005.

GRANDY, G.; MILLS, A. Strategy as simulacra? A radical reflexive look at the discipline and practice of strategy. Journal of Management Studies, v. 41, n. 7, p. 1153-1170, 2004.

GRANT, J.; MILLS, A. The quiet Americans: formative context, the Academy of Management leadership, and the management textbook, 1936-1960. Management \& Organizational History, v. 1, n. 2, p. 201-224, 2006.

GROSFOGUEL, R. The dilemmas of ethnic studies in the US: between liberal multiculturalism, identity politics, disciplinary colonization, and decolonial epistemologies. Human Architecture - Journal of the Sociology of SelfKnowledge, v. 10, n. 1, p. 9-27, 2012a.

Decolonizing Western uni-versalisms: decolonial pluri-versalism from Aimé Césaire to the zapatistas. Transmodernity, v. 2, n. 1, p. 88-104, 2012b.

GUEDES, A.; FARIA, A. Bring the 'international' into international management: new challenges. In: GUEDES, A.; FARIA, A. (Ed.). International management and international relations: a critical perspective from Latin America. New York: Routledge. 2010. p. 231-242.

HARVEY, D. The new imperialism. New York: Oxford University Press, 2003.

HELISTROM, I. The Chinese family in the communist revolution: aspects of the changes brought about by the communist government. Acta Sociologica, v. 6, n. 4, p. 256-277, 1962. 
IBARRA-COLADO, E. Organization studies and epistemic coloniality in Latin America: thinking otherness from the margins. Organization, v. 13, n. 4, p. 489-508, 2006.

INKELES, A. Exploring individual modernity. New York: Columbia University Press, 1983.

JACK, G. et al. Deepening, broadening and re-asserting a postcolonial interrogative space in organization studies. Organization, v. 18, n. 3, p. 275-302, 2011.

JACQUES, R. Manufacturing the employee: management knowledge from the $19^{\text {th }}$ to $21^{\text {st }}$ centuries. London: Sage, 1996.

KELlEY, E.; MILlS, A.; COOKE, B. Management as a Cold War phenomenon? Human Relations, v. 59, n. 5, p. 603-610, 2006.

KIESER, A. The americanization of academic management education in germany. Journal of Management Inquiry, v. 13, n. 2, p. 90-97, 2004.

KIPPING, M.; ÜSDIKEN, B.; PUIG, N. Imitation, tension, and hybridization: multiple "americanizations" of management education in Mediterranean Europe. Journal of Management Inquiry, v. 13, n. 2, p. 98-108, 2004.

KUHN, T. The structure of scientific revolutions. 2. ed. Chicago, IL: Chicago University Press, 1970.

LATOUR, B. Science in action. Cambridge, MA: Harvard University Press, 1987.

LOCKE, R. The collapse of the American management mystique. Oxford: Oxford University Press, 1996.

MAHBUBANI, K. The new Asian hemisphere: the irresistible shift of global power to the East. New York: Public Affairs, 2008

MCLAREN, P.; MILLS, A. A product of "his" time? Exploring the construct of the ideal manager in the Cold War era. Journal of Management History, v. 14, n. 4, p. 386-403, 2008.

MENNELL, S. Globalization and Americanization. In: TURNER, B. (Ed.). The Routledge international handbook of globalization studies. London: Routledge, 2010, p. 554-568.

MERKLE, J. Management and ideology: the legacy of the international scientific management movement. Berkeley: University of California Press, 1980.

MIGNOLO, W.; TLOSTANOVA, M. Theorizing from the borders: shifting to geo- and body-politics of knowledge. European Journal of Social Theory, v. 9, n. 2, p. 205-221, 2006.

Epistemic disobedience, independent thought and de-colonial freedom. Theory, Culture \& Society, v. 26, n. 7/8, p. 1-23, 2009.

The darker side of western modernity: global futures, decolonial options. London: Duke University Press,

Geopolitics of sensing and knowing: on (de)doloniality, border thinking, and epistemic disobedience. Confero, v. 1, n. 1, p. 129-150, 2013

MILLS, W. The power elite. New York: Oxford University Press, 1956.

MIZRUCHI, M. S. Berle and Means revisited: the governance and power of large U.S. corporations. Theory and Society, v. 33, p. 579-617, 2004.

MOORE, M. Societies, polities and capitalism in developing countries: a literature survey. Journal of Development Studies, v. 33, n. 3, p. 287-363, 1997. 
MOORE, K. Paradigms and theory building in the domain of business families. Family Business Review, v. 22, n. 2 , p. 167-180, 2009.

MOTTA, F.; CALDAS, M. (Ed.). Cultura organizacional e cultura brasileira. São Paulo: Atlas, 1997.

MOUSSEAU, M. Market civilization and its clash with terror. International Security, v. 27, n. 3, p. 5-29, 2003.

MURPHY, J.; ZHU, J. Neo-colonialism in the academy? Anglo-American domination in management journals. Organization, v. 19, n. 6, p. 915-927, 2012.

NYE, J. The decline of America soft power: why Washington should worry. Foreign Affairs, v. 83, n. 3, p. 16-20, 2004.

PAIVA, K.; OLIVEIRA, M.; MELO, M. Produção científica brasileira sobre empresa familiar - um metaestudo de artigos publicados em anais de eventos da ANPAD no período de 1997-2007. Revista de Administração Mackenzie, v. 9, n. 6, p. 148-173, 2008.

PARMAR, I. American foundations and the development of international knowledge networks. Global Networks, v. 2, n. 1, p. 13-30, 2002.

PERROW, C. Organizing America: wealth, power and the origins of corporate capitalism. Princeton: Princeton University Press, 2002.

PETTIGREW, A.; THOMAS, R.; WHITTINGTON, R. Strategic management: the strengths and limitations of a field. In: PETTIGREW, A.; THOMAS, R.; WHITTINGTON, R. (Ed.). The handbook of strategy and management. London: Sage, 2002. p. 4-30.

PIETERSE, J.; PETERS, M. Understanding the sources of anti-westernism: a dialogue between Jan Nederveen Pieterse and Michael A. Peters. Policy Futures in Education, v. 10, n. 1, 2012.

PORTER, M.; KRAMER, M. Strategy and society. Harvard Business Review, v. 84, n. 12, p. 78-92, 2011.

QUIJANO, A. Modernidad, colonialidad y América Latina. Neplanta - Views from the South, v. 1, n. 3, p. 533-580, 2000 .

; WALLERSTEIN, I. Americanity as a concept, or the Americas in the modern world-system. International Social Science Journal, v. 44, p. 529-549, 1992.

RODRIGUES, S.; CARRIERI, A. A tradição anglo-saxônica nos estudos organizacionais brasileiros. Revista de Administração Contemporânea, v. 5, p. 81-102, 2001.

ROSTOW, W. The stages of economic growth: a non-communist manifesto. Cambridge, MA: Cambridge University Press, 1960.

SANTOS, B.; NUNES, J.; MENESES, M. Opening up the canon of knowledge and recognition of difference. In: SANTOS, B. (Ed.). Another knowledge is possible: beyond northern epistemologies. New York: Verso, 2008. p. ixx1xii.

SMITH, T. The underdevelopment of development literature: the case of dependency theory. World Politics, v. 31 , n. 2, p. 247-288, 1979

SPECTOR, B. The Harvard Business Review goes to war. Management \& Organizational History, v. 1, n. 3 , p. $273-$ $295,2006$.

SPICER, A. Beyond the convergence-divergence debate: the role of spatial scales in transforming organizational logic. Organization Studies, v. 27, n. 10, p. 1467-1483, 2006.

STEGER, M. Globalisms. New York: Rowman \& Littlefield, 2009. 
. ; ROY, R. Neoliberalism: a very short introduction. Oxford: Oxford University Press, 2010.

STIGLITZ, J. Globalization and its discontents. New York: W. W. Norton, 2002.

TAYLOR, F. Principles of scientific management. New York: Harper Bros., 1911.

TUASTAD, D. Neo-Orientalism and the new barbarism thesis: aspects of symbolic violence in the Middle East conflict(s). Third World Quarterly, v. 24, n. 4, p. 591-599, 2003.

USEEM, M. The social organization of the American business elite and participation of corporate directors in the governance of American institutes. American Sociological Review, v. 44, p. 553-572, 1979.

WALLERSTEIN, I. Eurocentrism and its avatars: the dilemmas of social science. New Left Review, v. 226, p. 93-108, 1997.

WALSH, C. Development as buen vivir: institutional arrangements and (de)colonial entanglements. Development, v. 53 , n. 1 , p. $15-21,2010$.

WANDERLEY, S.; FARIA, A. The Chandler-Furtado case: a decolonial (re)framing of a North/South (dis)encounter. Management \& Organizational History, v. 7, n. 3, p. 219-236, 2012.

WEAVER, R.; ROCKMAN, B. Do institutions matter? Government capabilities in the United States and abroad. Washington, DC: Brookings Institution Press, 1993. 